\title{
Viabilidade agronômica de consórcios de brócolis e alface estabelecidos em diferentes épocas
}

\author{
Agronomic feasibility of broccoli and lettuce intercropping established \\ in different growing periods
}

\author{
Silvana Ohse ${ }^{1}$, Bráulio Luciano Alves Rezende ${ }^{2}$, Lucas Sleutjes Silveira ${ }^{3}$, \\ Rosana Fernandes Otto ${ }^{1 *}$, Marluce Gonçalves Cortez ${ }^{1}$
}

\section{RESUMO}

A produção de hortaliças cresce acentuadamente, decorrente do aumento do consumo entre outras razões, da busca por alimentos mais saudáveis. Objetivou-se verificar a viabilidade agronômica do consórcio entre brócolis e alface, em função do sistema de cultivo e época de estabelecimento do consórcio. O ensaio foi realizado em Ponta Grossa, PR, Brasil, o qual constou de 11 tratamentos, resultantes da combinação dos fatores sistemas de cultivo (monocultura e consórcio) e épocas de transplante da alface [0, 7, 14, 21, 28 dias após o transplante (DAT) do brócolis], conduzido em delineamento de blocos casualizados com quatro repetições. A produtividade e classificação das "cabeças" de brócolis em cultivo consorciado, independente da época de estabelecimento do consórcio, não diferiram das obtidas em monocultura. A produtividade das plantas de alface foi influenciada pela época de estabelecimento do consórcio. As plantas de alface cultivadas em consórcio aos 28 DAT do brócolis não apresentaram qualidade comercial. $\mathrm{O}$ índice de eficiência no uso da área foi influenciado pela época de transplante da alface, sendo reduzido à medida que se atrasou o mesmo. Os consórcios estabelecidos até 14 DAT do brócolis foram viáveis agronomicamente em relação a ambas culturas (alface e brócolis) produzidas isoladamente.

Palavras clave: Lactuca sativa L., Brassica oleracea var. italica, sistemas de cultivo, momento de transplante.

\begin{abstract}
The production of vegetables is growing rapidly because of increased consumption, due to, among other reasons, the desire for healthy eating. To evaluate the feasibility of broccoli and lettuce intercropping as a function of the growing system and the establishment time of the intercropping, an experiment was conducted in Ponta Grossa, PR, Brazil, which consisted of 11 treatments of the combination of cropping systems (monoculture and intercropping) and lettuce transplanting time (0, 7, 14, 21, 28 days after broccoli transplantation - DAT), conducted in a randomized block design with four replications. The yield of broccoli heads under intercropping did not differ from the monoculture, independent of the establishment time period of the intercropping. The lettuce yield was affected by the establishment time of the intercropping. The lettuce plants grown in intercropping at 28 DAT of broccoli did not have commercial quality. The index of efficiency in the use of the area was influenced by the time of transplant lettuce, being reduced to the extent that transplanting of lettuce was delayed. The intercropping established up to 14 DAT of broccoli are agronomically feasible in relation to their monocultures (broccoli and lettuce).
\end{abstract}

Key words: Lactuca sativa $L$., Brassica oleracea var. italica, cropping systems, transplantation time.

\section{Introdução}

Atualmente o consumo de hortaliças tem aumentado devido à crescente conscientização da população em busca de dieta alimentar mais rica e saudável. Desse modo, o desenvolvimento de sistemas de cultivo de hortaliças, com vistas à otimização da produtividade, tem exigido dos agricultores esforços no sentido de minimizar ou até mesmo eliminar as deficiências do setor produtivo (Montezano \& Peil, 2006).

Sistemas consorciados são aqueles em que, duas ou mais espécies vegetais, com diferentes ciclos e arquitetura, ocupam uma mesma área em

1 Engenheiras Agrônomas, Professoras Doutoras do Departamento de Fitotecnia e Fitossanidade da Universidade Estadual de Ponta Grossa, Campus Uvaranas - 4748, Ponta Grossa - PR, Brasil, CEP: 84030-900. E-mail: sohse@ uepg.br*

2 Engenheiro Agrônomo, Prof. Adjunto Dr., Instituto Federal do Espírito Santo/Campus de Vila Velha, Av. Ministro Salgado Filho, s/no ${ }^{-}$, Soteco. Vila Velha-ES, Brasil, CEP:29106-010.

3 Acadêmico do curso de Agronomia da Universidade Estadual de Ponta Grossa, Campus Uvaranas - 4748, Ponta Grossa - PR, Brasil, CEP: 84030-900.

Fecha de Recepción: 27 Febrero, 2012

Fecha de Aceptación: 18 Mayo, 2012. 
dado período de tempo, não necessitando semeadura simultânea (Gliessman, 2005). O cultivo consorciado é empregado, sobretudo, pelos pequenos agricultores, na procura em aproveitar ao máximo as áreas de que dispõem; dos insumos e da mão de obra em capinas, adubações, aplicações de defensivos e outros tratos culturais (Caetano et al., 1999), obtendo maior diversificação e rentabilidade por unidade de área (Bezerra Neto et al., 2001; Barros Júnior et al., 2009).

Kolmans \& Vásquez (1999), destacam como vantagens destes sistemas o melhor uso do solo, da água e da área cultivada; minimização de problemas com pragas e doenças, melhorando o manejo no controle de plantas daninhas. Muller et al. (2000), citam ainda, que há melhor aproveitamento da radiação solar, minimizando riscos de perdas das culturas consorciadas em função do clima.

A escolha das culturas componentes e da época de estabelecimento das mesmas é fundamental para a obtenção de máxima vantagem no consórcio. A época de estabelecimento é fundamental no planejamento desses cultivos, pois o período de convivência entre as espécies pode afetar a produtividade das culturas envolvidas (Cecílio Filho \& May, 2002).

Poucos autores correlacionam consórcios e épocas de estabelecimento entre as espécies. A época de transplante de uma cultura em relação à outra é fator importante no estabelecimento de cultivos consorciados (Cecílio Filho \& May, 2002).

Avaliando o efeito da consorciação e épocas de semeadura de chicória e rúcula, Cecílio Filho et al. (2008a) observaram que a rúcula, independentemente da época em que foi semeada, não influenciou a produtividade da chicória. Rezende et al. (2005) consorciando tomate e alface, constataram que a redução nas fitomassas fresca e seca de tomate foi influenciada pela época do transplante da alface.

Rezende et al. (2003) verificaram maior produtividade do rabanete consorciado aos 14 DAT da alface, sendo $26 \%$ superior à monocultura. A redução da fitomassa fresca da parte aérea de alface evidenciou a influência de maior competição interespecífica com rabanete, sendo maior, quanto mais tarde se estabeleceu o consórcio.

A utilização de espécies contrastantes é importante para se maximizar a complementaridade entre as espécies e minimizar a competição interespecífica, peculiar a cultivos consorciados (Cecílio Filho et al., 2005). Segundo esses autores, para obtenção de sucesso em cultivos consorciados, é de suma importância a escolha de espécies contrastantes em uma ou mais características. Por essa razão, a alface e o brócolis foram selecionados para compor os cultivos consorciados. Diante do exposto, objetivou-se avaliar a viabilidade agronômica do consórcio de brócolis e alface em função do sistema de cultivo (consórcio e monocultura) e da época de estabelecimento do consórcio.

\section{Material e Métodos}

O experimento foi conduzido no setor de Olericultura da Universidade Estadual de Ponta Grossa (UEPG), de maio a agosto de 2010. Avaliaramse 11 tratamentos, resultantes da combinação dos fatores sistemas de cultivo (monocultura do brócolis e da alface e seu consórcio) e épocas de transplante da alface $(0,7,14,21,28$ dias após o transplante [DAT] do brócolis), conforme Tabela 1.

Em monocultura, as unidades experimentais com alface e brócolis foram constituídas por $28 \mathrm{e}$ 24 plantas, perfazendo uma área total de $2,52 \mathrm{~m}^{2}$ $(1,20 \times 2,10 \mathrm{~m})$ e $11,52 \mathrm{~m}^{2}(3,60 \times 3,20 \mathrm{~m})$, respectivamente. No cultivo consorciado, as unidades experimentais foram constituídas por 24 plantas de brócolis e 33 plantas de alface, perfazendo uma área total de $11,52 \mathrm{~m}^{2}(3,60 \times 3,20 \mathrm{~m})$.

A análise química de solo foi realizada no Laboratório de Fertilidade do Solo da UEPG. A análise química do solo apresentou $\mathrm{pH}\left(\mathrm{CaCl}_{2}\right)$ de 6,$0 ; 22 \mathrm{~g} \mathrm{dm}^{-3}$ de carbono orgânico; $34,5 \mathrm{mg} \mathrm{dm}^{-3} \mathrm{de}$ fósforo (Mehlich-1). Em cmolc dm ${ }^{-3}$, observou-se 0,40 de potássio; 5,3 de cálcio e 2,8 de magnésio, saturação por bases de $71,3 \%$.

Foi realizada calagem, utilizado calcário dolomítico, PRNT 95,2\%, visando elevação da saturação de bases a $80 \%$. A adubação mineral de plantio para ambas as culturas correspondeu à aplicação de $600 \mathrm{~kg} \mathrm{ha}^{-1}$ da fórmula 10-20-20, conforme recomendação de Raij et al. (1997). A adubação de plantio foi realizada na data de transplante de cada cultura, porém para os tratamentos em consórcio a adubação mineral de plantio foi realizada em área total na data do transplante do brócolis, independentemente da época de transplante da alface.

Para a cultura do brócolis, realizou-se adubação de cobertura aplicando-se $500 \mathrm{~kg} \mathrm{ha}^{-1}$ da fórmula 36-00-12, parcelada aos $15,30,45$ e 60 DAT. Também foi realizada adubação foliar com molibdato de amônio $\left(0,5 \mathrm{~g} \mathrm{~L}^{-1}\right)$ aos 15 DAT e ácido bórico $\left(1 \mathrm{~g} \mathrm{~L}^{-1}\right)$ aos 30,45 e 60 DAT. Para a cultura da 
alface, a adubação de cobertura foi realizada com aplicação de $60 \mathrm{~kg}$ de $\mathrm{N} \mathrm{ha}^{-1}$, na forma de uréia, parcelada aos 15 e $30 \mathrm{DAT}$, independentemente das épocas de transplante da alface.

Para o brócolis foi utilizado a cultivar híbrida Avenger e para a alface a cultivar Vanda. Em ambos os sistemas de cultivo, as mudas de brócolis foram transplantadas no espaçamento de $0,80 \times 0,60 \mathrm{~m}$. Para a alface, os espaçamentos utilizados foram de $0,30 \times 0,30 \mathrm{~m}$ e $0,80 \times 0,30 \mathrm{~m}$, respectivamente, para o cultivo em monocultura e consórcio. O transplante das mudas de brócolis e alface referente à primeira época de cultivo (0 DAT) foi realizado no dia 11/05/2010, por conseguinte, foram realizados os transplantes da alface aos 7, 14, 21 e 28 DAT do brócolis, conforme constam os tratamentos (Tabela 1).

O preparo do solo constou de uma aração e duas gradagens. O controle de plantas daninhas durante a condução experimental foi realizado através de capinas manuais. Utilizou-se, durante todo o ciclo das culturas, irrigação por aspersão. Não houve necessidade de tratamentos fitossanitários durante o ciclo das culturas.

A área útil utilizada nas parcelas compreendeu a área central ocupada por 6 plantas, sendo de $0,54 \mathrm{~m}^{2}$ e $1,44 \mathrm{~m}^{2}$ para alface cultivada em monocultura e consórcio, respectivamente, enquanto para o brócolis foi de 2,88 $\mathrm{m}^{2}$, em ambos os sistemas de cultivo. A colheita da alface, em todas as épocas de transplante, foi realizada aos 56 DAT e do brócolis, aos 84 DAT. As características avaliadas para alface foram: altura de planta (AP), comprimento de caule (CC), diâmetro longitudinal (DLPA) e transversal da parte aérea (DTPA), número de folhas por planta (NFP), fitomassa fresca e seca da parte aérea de plantas (FMFPA e FMSPA).
Para todas as épocas de transplante da alface em relação ao brócolis foram mensurados a campo: AP, DLPA e DTPA, na data da colheita, com auxílio de régua graduada. Depois de destacadas do caule, as folhas foram contadas, considerando-se somente as com comprimento superior a $5 \mathrm{~cm}$. Em seguida, procedeu a medição do $\mathrm{CC}$ com auxílio de régua graduada, realizada desde a base de corte na superfície do solo até o ápice do caule. A FMFPA das plantas foi obtida através de pesagem em balança de precisão, logo após a colheita. Após a separação de folhas e caule, estes foram colocados em sacos de papel e levados a estufa de circulação de ar forçada a $60{ }^{\circ} \mathrm{C}$, por 96 horas, obtendo assim, a FMSPA.

Para o brócolis foram avaliados o diâmetro de "cabeça" (DC), fitomassa fresca e seca de "cabeça" (FMFC e FMSC). O DC de brócolis foi mensurado em laboratório com auxílio de régua graduada. A FMFC foi obtida em laboratório através de pesagem em balança de precisão. Após esta etapa, as "cabeças" de brócolis foram submetidas à secagem em estufa de circulação de ar forçado a $60{ }^{\circ} \mathrm{C}$ durante 7 dias, determinando-se então, a FMSC.

O índice de uso eficiente da área (UEA), utilizado para avaliar a eficiência do consórcio em relação às monoculturas, foi obtido pela expressão: $\mathrm{UEA}=(\mathrm{Cb} /$ $\mathrm{Mb})+(\mathrm{Ca} / \mathrm{Ma})$, onde $\mathrm{Cb}$ e Ca são, respectivamente, as produtividades em consorciação das culturas de brócolis e alface e Mb e Ma são as produtividades em monocultura das culturas de brócolis e alface, respectivamente. Para o cálculo do UEA foram utilizados os valores de produtividade com base em uma área efetiva de $1 \mathrm{~m}^{2}$ para as monoculturas e os consórcios.

Para interpretação dos dados das características relativas ao brócolis, efetuou-se a análise de

Tabela 1. Caracterização dos tratamentos avaliados no experimento. Ponta Grossa - PR, UEPG, 2010.

\begin{tabular}{llc}
\hline Tratamentos & Brócolis & Alface $\left(\right.$ DAT $\left.^{*}\right)$ \\
\hline 1 - Consórcio & Presente & 0 \\
2 - Consórcio & Presente & 7 \\
3 - Consórcio & Presente & 14 \\
4 - Consórcio & Presente & 21 \\
5 - Consórcio & Presente & 28 \\
6 - Monocultura Brócolis & Presente & Ausente \\
7 - Monocultura Alface & Ausente & 7 \\
8 - Monocultura Alface & Ausente & 14 \\
9 - Monocultura Alface & Ausente & 21 \\
10 - Monocultura Alface & Ausente & 28 \\
11 - Monocultura Alface & Ausente & \\
\hline
\end{tabular}

*Dias após transplante do brócolis. 
variância sob delineamento de blocos casualizados (DBC), com 4 repetições e 6 tratamentos, os quais corresponderam ao brócolis em monocultura e 5 consórcios com a alface $(0,7,14,21$ e 28 DAT). Para as características relativas à alface, a análise de variância também foi sob DBC, com 4 repetições, em esquema fatorial 5 (épocas de semeadura de alface aos 0, 7, 14, 21 e 28 DAT do brócolis) x 2 sistemas de cultivo (consórcio e monocultura), analisadas através do programa ESTAT.

As análises de variância dos dados do UEA foram realizadas com 5 tratamentos $(0,7,14,21 \mathrm{e}$ 28 DAT do brócolis), sob DBC, com 4 repetições. Para época de estabelecimento da alface em relação ao transplante do brócolis foi realizada análise de regressão, definindo o melhor ajuste segundo combinação de significância e maior coeficiente de determinação. Para o índice de uso eficiente da área o estudo de regressão foi realizado em função da época de transplante da alface em relação ao brócolis.

\section{Resultados e Discussão}

A FMFC, FMSC e DC de plantas de brócolis não foram influenciadas significativamente pelos sistemas de cultivo com a alface. A FMFC de brócolis foi de $0,968 \mathrm{~kg}_{\text {planta }}{ }^{-1}$, correspondendo à produtividade de $20.167 \mathrm{~kg} \mathrm{ha}^{-1}$. Os valores médios de FMSC e do DC de brócolis foram de 64,27 $\mathrm{g}$ e $25,96 \mathrm{~cm}$, respectivamente (Tabela 2).

A presença da alface, independente da época em que foi transplantada, não influenciou o crescimento do brócolis (Tabela 2). Este efeito provavelmente ocorreu devido ao contraste entre o ciclo das espécies, porte, arquitetura, velocidade de crescimento e ocupação da área. O desenvolvimento lento da alface nos primeiros 20 DAT permitiu ao brócolis atingir altura suficiente para não sofrer influência com a sua presença, asseverando que o brócolis foi indiferente à alface (Tabela 2). Resultados semelhantes foram encontrados nos cultivos consorciados de cebola e alface (Paula et al., 2009), pimentão e alface (Rezende et al., 2006), pepino e alface (Rezende et al., 2010) e entre tomate e alface (Rezende et al., 2005; Cecílio Filho et al., 2008b). Nesses estudos, a produtividade e classificação de bulbos de cebola e de frutos de tomate e pepino não foram influenciados pela presença da alface.

Para as variáveis AP, DLPA, DTPA, NFP, FMFPA, FMSPA $(\mathrm{p}<0,01)$ e CC de plantas de alface $(p<0,05)$ houve interação entre sistema de cultivo e época de transplante da alface em relação ao brócolis. A AP de alface cultivadas em consórcio apresentou ajuste de equação polinomial de segundo grau em função do atraso no transplante. Por outro lado, em monocultura, não houve influencia das épocas de transplante sobre a AP de alface, apresentando altura média de 20,23 cm (Figura 1).

Plantas de alface transplantadas no mesmo dia do transplante do brócolis, apresentou AP de $23,50 \mathrm{~cm}$, decrescendo até os 14 DAT do brócolis, quando apresentou altura mínima de $20,52 \mathrm{~cm}$, correspondendo a $12,68 \%$ de redução. A partir de então, houve acréscimos na AP de alface até os 28 DAT, quando atingiu maior valor $(23,70 \mathrm{~cm})$. Independentemente da época de transplante, a AP de alface em consórcio foi maior do que em monocultura (Figura 1).

O brócolis, por apresentar maior AP, sombreou as plantas de alface, causando estiolamento após os 14 DAT do brócolis, o que pode ser atribuído

Tabela 2. Fitomassa fresca (FMFPA) e seca (FMSPA) da parte aérea e diâmetro da "cabeça" (DC) de plantas de brócolis 'Avenger', em função dos sistemas de cultivo. Ponta Grossa - PR, UPEG, 2011.

\begin{tabular}{llcc}
\hline \multicolumn{1}{c}{ Sistemas de Cultivo } & FMF $(\mathrm{kg})$ & FMS $(\mathrm{g})$ & DC $(\mathrm{cm})$ \\
\hline Monocultura brócolis & $1,012 \mathrm{a}^{2}$ & $67,20 \mathrm{a}$ & $27,00 \mathrm{a}$ \\
Consórcio 0 DAT $^{1}$ & $0,959 \mathrm{a}$ & $63,66 \mathrm{a}$ & $25,75 \mathrm{a}$ \\
Consórcio 7 DAT & $0,972 \mathrm{a}$ & $64,55 \mathrm{a}$ & $26,25 \mathrm{a}$ \\
Consórcio 14 DAT & $0,881 \mathrm{a}$ & $58,48 \mathrm{a}$ & $23,50 \mathrm{a}$ \\
Consórcio 21 DAT & $1,006 \mathrm{a}$ & $66,78 \mathrm{a}$ & $26,75 \mathrm{a}$ \\
Consórcio 28 DAT & $0,978 \mathrm{a}$ & $64,94 \mathrm{a}$ & $26,50 \mathrm{a}$ \\
Média & $0,968 \mathrm{a}$ & $64,27 \mathrm{a}$ & $25,96 \mathrm{a}$ \\
CV\% & 9,09 & 9,11 & 8,92 \\
\hline
\end{tabular}

${ }^{1}$ DAT = dia após o transplante do brócolis; ${ }^{2}$ Médias nas colunas, seguidas por letras iguais, não diferem entre si pelo Teste Tukey a $5 \%$ de probabilidade. 


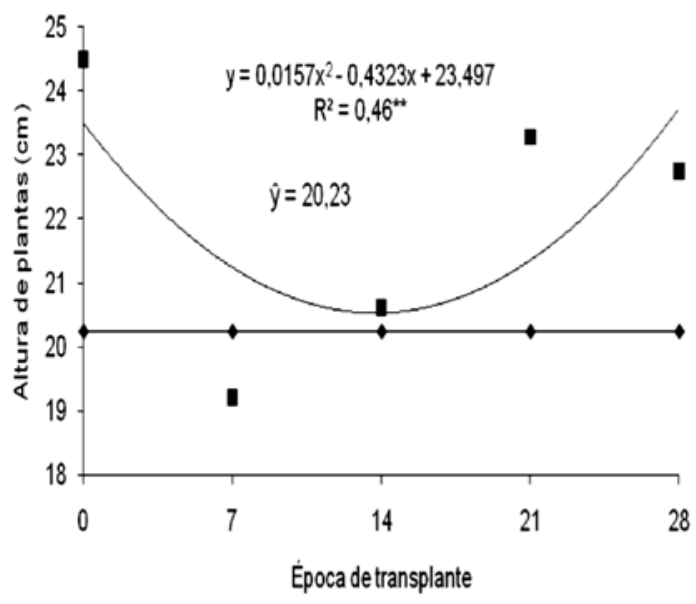

- Monocultura alface Consórcio brócolis x alface

Figura 1. Altura de plantas de alface 'Vanda' em função da época de transplante da alface em relação ao brócolis 'Avenger'. Ponta Grossa - PR, UEPG, 2011.

à competição interespecífica, principalmente por luz (Figura 1). A AP de alface aos 0 e 7 DAT do brócolis foram maiores, porém as plantas não se apresentaram estioladas. Este fato, também pode ser justificado pelo maior DLPA, DTPA, NFP, FMFPA e FMSPA apresentada pelas plantas de alface quando transplantadas conjuntamente com o brócolis (0 DAT), o que pode ser observado nas Figuras 5, 6, 7, 8 e 9, respectivamente.

No presente trabalho, a competição entre plantas provavelmente foi maior pela luminosidade do que por água e nutrientes. Haja vista que as plantas em ambos os sistemas de cultivo foram irrigadas durante todo o ciclo e receberam todas as adubações necessárias. Competição interespecífica, principalmente com relação à luz foi observada também Rezende et al. (2006), quando do consórcio entre pimentão, repolho, rúcula, alface e rabanete, uma vez que a AP de alface foi menor quando consorciada com pimentão e rúcula do que quando consorciada com pimentão e repolho.

Diferentemente, Oliveira et al. (2010) observaram que a $\mathrm{AP}$ de alface cultivadas em monocultura foi semelhante à obtida em consórcio com rúcula.

O CC foi influenciado significativamente pela interação dos fatores sistemas de cultivo e época de transplante de alface em relação ao brócolis $(\mathrm{p}<0,05)$. No sistema consorciado, o CC apresentou comportamento semelhante à monocultura, porém, com reduções acentuadas até 16 DAT do brócolis

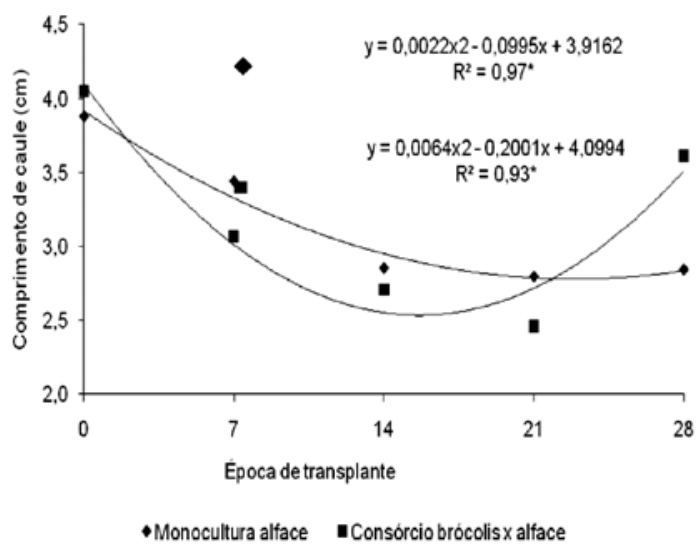

Figura 2. Comprimento de caule de plantas de alface 'Vanda' em função da época de transplante da alface em relação ao brócolis 'Avenger'. Ponta Grossa-PR, UEPG, 2011.

(Figura 2). Maior CC também foi observado ao 0 DAT, decrescendo até aos 16 DAT, correspondendo à redução de $38,05 \%$. A partir deste ponto houve incremento de $38,19 \%$ até aos 28 DAT do brócolis (Figura 2).

Quando uma planta está sob outra a quantidade de luz que alcança suas folhas pode se tornar limitante, comprometendo severamente o crescimento de caules e folhas (Gliessman, 2005). Em monocultura, o CC decresceu de 3,92 cm (0 DAT) até $2,79 \mathrm{~cm}$ (23 DAT), ou seja, 26,8\% de redução. Em seguida houve aumento de $2,4 \%$ até os 28 DAT (Figura 2). A redução no CCA não influenciou a AP da alface em monocultura (Figura 1), pois se manteve constante em função das épocas de transplante.

Em monocultura, o DLPA decresceu em $3,07 \mathrm{~cm}$ entre 0 e 28 DAT do brócolis. Quando as plantas de alface foram cultivadas em consórcio com o brócolis, o atraso no transplante proporcionou redução mais acentuada que a obtida para alface em monocultura $(10,40 \%)$ (Figura 3).

Resultado semelhante ao obtido para DLPA foi observado para DTPA de plantas de alface, pois houve ajuste linear decrescente tanto para monocultura como consórcio em função da época de transplante da alface em relação ao brócolis (Figura 4). Em monocultura, a redução no DTPA foi gradativa conforme se atrasou o transplante da alface, porém com valores inferiores aos obtidos em consórcio até 15 DAT (Figura 4). Em consórcio, o maior DTPA também foi obtido ao 0 DAT $(34,39 \mathrm{~cm})$, apresentando redução de $34,54 \%$ em relação ao DTPA obtido aos 28 DAT $(22,84 \mathrm{~cm})$, 


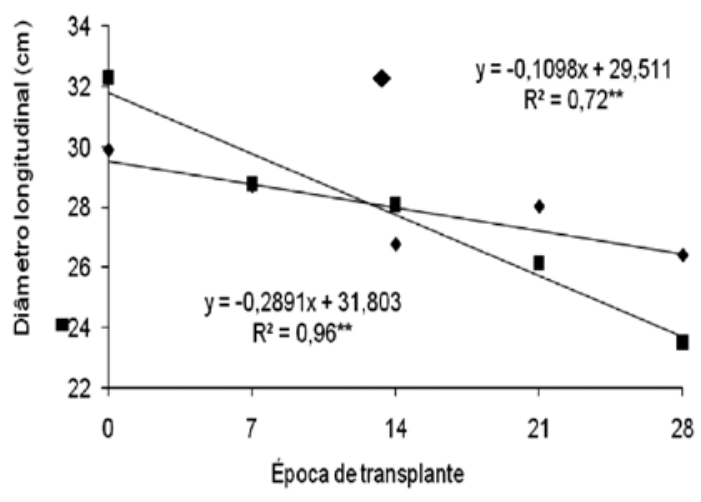

- Monocultura alface a Consórcio brócolis x alface

Figura 3. Diâmetro longitudinal da parte aérea de plantas de alface 'Vanda' em função da época de transplante da alface em relação ao brócolis ‘Avenger'. Ponta Grossa-PR, UEPG, 2011.

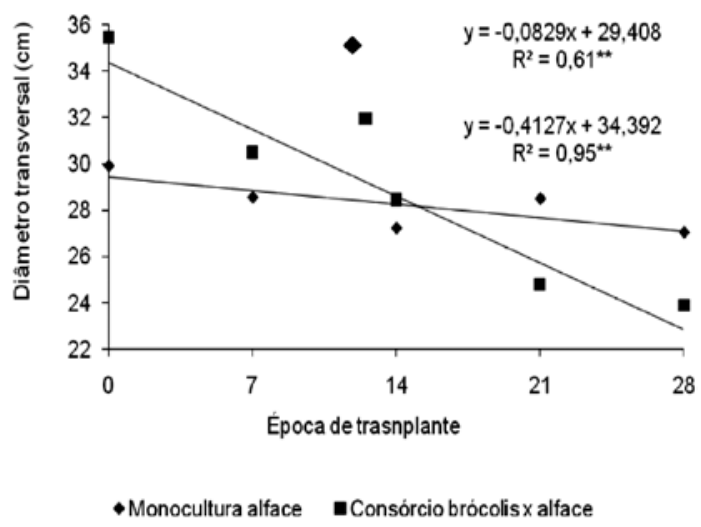

Figura 4. Diâmetro transversal da parte aérea de plantas de alface 'Vanda' em função da época de transplante da alface em relação ao brócolis 'Avenger'. Ponta Grossa-PR, UEPG, 2011.

redução esta, superior a apresentada para as plantas cultivadas em monocultura $(7,89 \%)$.

A redução observada no DTPA de alface consorciada com o brócolis em função do atraso do transplante foi maior do que a redução observada no DLPA, sendo esta diferença de $9,10 \%$. Tal fato, pode ser justificado pela sobreposição das folhas do brócolis sobre a alface, fazendo com que esta se desenvolvesse mais no sentido longitudinal do que transversal. Resultados semelhantes para DTPA de alface foram obtidos por Bezerra Neto et al. (2003) no cultivo consorciado entre alface e cenoura.

Rezende et al. (2006) observaram que o diâmetro de plantas de alface foi significativamente reduzido no consórcio entre pimentão+repolho+alface, quando comparado com pimentão+alface. Resultado atribuído a maior competição por luz no consórcio estabelecido com repolho, devido ao maior sombreamento da alface, diminuindo assim seu diâmetro. Semelhante ao observado neste estudo, pois as folhas do brócolis apresentaram crescimento mais rápido, sombreando em maior intensidade as plantas de alface quanto mais se atrasou o transplante da alface, o que levou as plantas de alface a apresentarem maior CCA e menor DLPA e DTPA (Figuras 4, 5 e 6).

O NFPA foi influenciado pela interação entre sistemas de cultivo e época de transplante da alface em relação ao brócolis. O NFPA em monocultura foi superior à obtida em consórcio para todas as épocas de transplante da alface (Figura 5). Maior NFPA foi obtido ao 0 DAT $(22,18)$, decrescendo em duas folhas por planta até os 19 DAT e incremento posterior de uma folha aos 28 DAT.

Em consórcio, maior NFPA também foi observado ao 0 DAT, apresentando redução de 38,22\% aos 28 DAT (Figura 5). Entretanto, a redução foi evidente e acentuada a partir dos 7 DAT, o que ocorreu devido à competição interespecífica entre brócolis e alface ser mais intensa a partir deste momento. Estes resultados corroboram com resultados obtidos para FMFPA e FMSPA (Figuras 8 e 9).

Redução do NFPA de alface quando consorciada com tomate também foi observada por Cecílio Filho et al. (2008b), sendo aumentada à medida que se atrasou o transplante da alface em relação ao tomate. Rezende et al. (2006) também observaram menor NFPA de plantas de alface cultivadas em consórcios

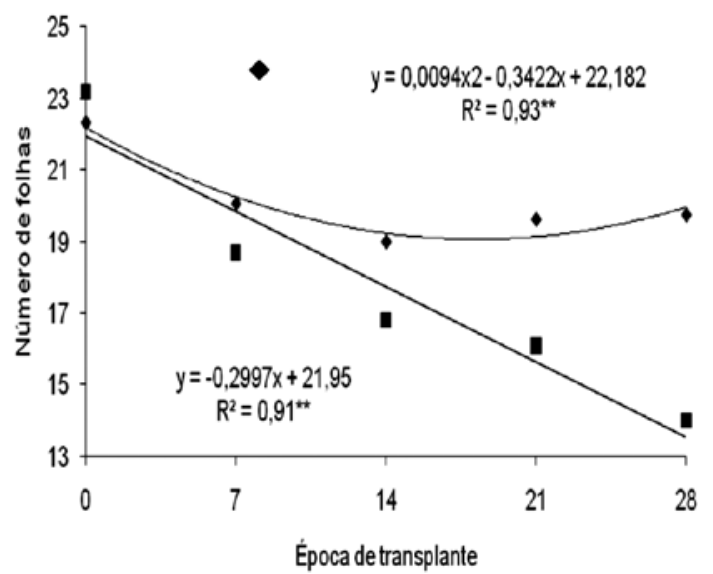

- Monocultura alface IConsórcio brócolis x alface

Figura 5. Número de folhas por planta de alface 'Vanda' em função da época de transplante da alface em relação ao brócolis 'Avenger'. Ponta Grossa-PR, UEPG, 2011. 
come pimentão+repolho quando comparado com pimentão+alface e de pimentão+rúcula, o que se deve à maior competição interespecífica entre repolho e alface.

O NFPA é um fator decisivo para aumento ou redução da FMFPA e FMSPA. O atraso na época de transplante da alface em relação ao brócolis implicou em reduções no NFPA e, consequentemente, na FMFPA de plantas de alface (Figura 6). Em monocultura, a FMFPA das plantas de alface foi reduzida em $51,62 \%$, ou seja, de $311,71 \mathrm{~g}$ planta $^{-1}\left(0\right.$ DAT) para 150,80 g planta $^{-1}$ obtida aos 28 DAT (Figura 6). Esta redução se deve aos fatores ambientais, principalmente baixas temperaturas, ocorridos durante a condução do experimento, os quais propiciaram melhor desenvolvimento das plantas quando estas foram transplantadas ao $0 \mathrm{e}$ 7 DAT do brócolis.

No intervalo de 0 a 6 DAT, a produção de FMFPA em monocultura foi menor que a obtida em consórcio, apresentando-se superior a partir dos 7 DAT (Figura 6). Este efeito demonstra que até 6 DAT houve uma complementaridade entre as espécies envolvidas no consórcio, proporcionado, assim, melhor desenvolvimento das plantas de alface $\mathrm{e}$, consequentemente, maior incremento de FMFPA.

Quando o transplante da alface em consórcio foi realizado após 7 DAT, as plantas de brócolis apresentavam-se mais desenvolvidas, o que favoreceu maior competição intraespecífica por água, nutrientes e principalmente por luz. O sombreamento ocasionados pelas folhas do brócolis sobre as

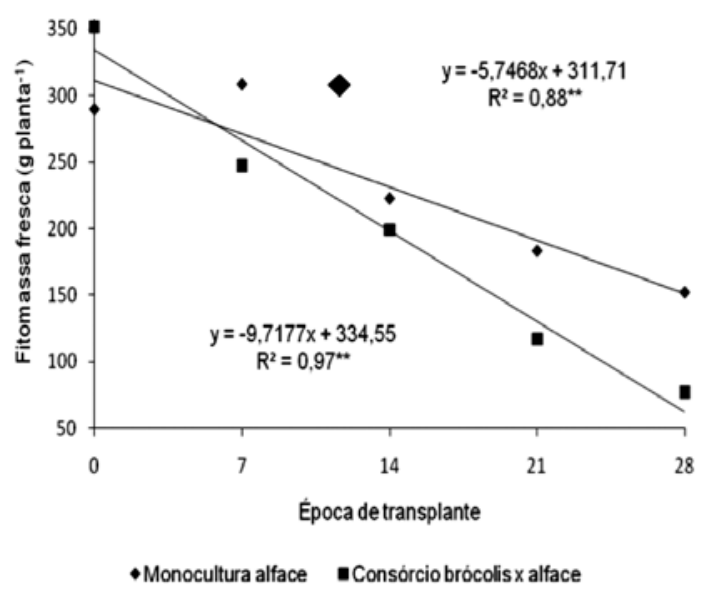

Figura 6. Fitomassa fresca da parte aérea de plantas de alface 'Vanda' em função da época de transplante da alface em relação ao brócolis ‘Avenger'. Ponta Grossa-PR, UEPG, 2011. plantas de alface favoreceu para a redução da taxa fotossintética e, consequentemente, influenciou o desenvolvimento da planta de alface, sendo observado tal efeito pela elevada redução da FMFPA aos 28 DAT $(81,33 \%)$.

Assim, quanto mais se atrasou o transplante da alface em relação ao brócolis menor foi o grau de complementaridade temporal. Pois a alface teve desde o início de seu desenvolvimento menor intensidade de radiação solar disponível e, consequentemente, a assimilação líquida (produção e consumo de fotoassimilados) foi reduzindo com o transplante da alface.

Resultados semelhantes foram encontrados por Rezende et al. (2010), no consórcio de pepino e alface, e por Rezende et al. (2005) e Cecílio Filho et al. (2008b), consórcio de tomate e alface, os quais verificaram reduções na FMFPA de plantas de alface progressivamente na medida em que se atrasou o transplante da alface.

A produtividade é intensamente dependente da interceptação de luz. De acordo com Sinoquet \& Celdwell (1995), a variação no acesso à luz pela cultura sombreada, devido à ocupação do espaço pela cultura dominante, pode acarretar sérios prejuízos à primeira, podendo até ser letal. Midmore (1993) relata que a alteração na época de plantio de uma das culturas e, portanto, no estabelecimento do consórcio, modifica o período de complementaridade e competição das culturas em consorciação, com reflexo na produtividade.

Em relação à FMSPA, houve incremento de 2,19 g planta $^{-1}$ durante o período de 0 a 10 DAT e, a partir deste ponto, houve redução de FMSPA (Figura 7). Semelhantemente a FMFPA, a FMSPA em consórcio foi influenciada pela época de transplante da alface, pois se ajustou a uma equação linear decrescente, passando de 16,12 g (0 DAT) para $4,06 \mathrm{~g} \mathrm{planta}^{-1}$ aos 28 DAT, o que corresponde a $74,81 \%$ de redução (Figura 7).

O consórcio estabelecido aos 28 DAT não permitiu que as plantas de alface se desenvolvessem satisfatoriamente, o que pode ser observado pelo menor DTPA, DLPA, NFPA, FMFPA e FMSPA, apresentando-se estioladas e com estreitamento do limbo foliar. Sob estas condições as plantas de alface colhidas encontravam-se completamente desfiguradas, sem caracterização e, consequentemente, sem valor comercial.

Neste contexto, Fukai \& Trenbath (1993) relatam que o sombreamento de uma cultura pela 


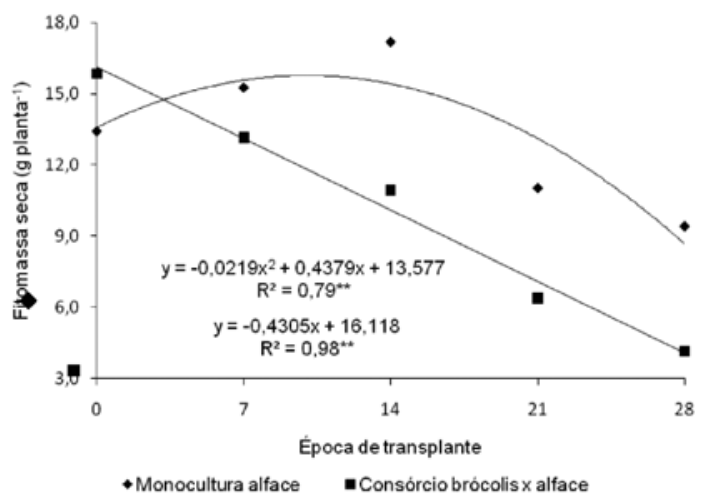

Figura 7. Fitomassa seca da parte aérea de plantas de alface 'Vanda' em função da época de transplante da alface em relação ao brócolis 'Avenger'. Ponta Grossa-PR, UEPG, 2011.

de maior porte, no consórcio, reduz a captação de radiação fotossinteticamente ativa pela cultura sombreada, resultando em menor crescimento e produtividade. Em todos os consórcios, os índices de eficiência no uso da área (EUA) apresentaram valores superiores a 1,0 , denotando vantagem dos consórcios em relação às monoculturas, pelo fato de aumentar a quantidade de alimento produzida na mesma unidade de área, inferindo-se que nessas condições houve melhor aproveitamento dos recursos disponíveis no ambiente de cultivo (Figura 8).

O EUA foi influenciado pela época de transplante da alface em relação ao transplante do brócolis. Quanto mais tardio foi o transplante da alface em relação ao brócolis menor foi o valor do índice de uso da área (Figura 8). O estabelecimento do consórcio ao 0 DAT mostrou-se mais vantajoso aos demais consórcios devido a maior produção de alimento por unidade de área.

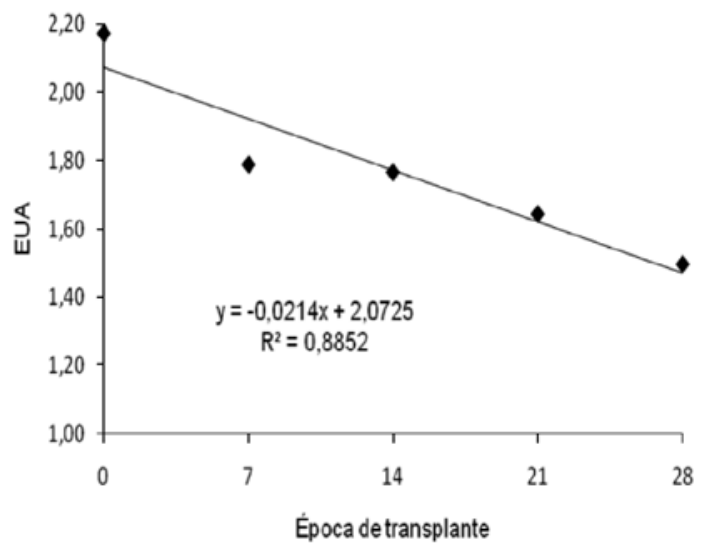

Figura 8. Índice de eficiência no uso da área (EUA) para o consorcio entre brócolis e alface em função da época de transplante da alface 'Vanda' em relação ao brócolis 'Avenger'. Ponta Grossa-PR, UEPG, 2011.

\section{Conclusões}

A produtividade e tamanho de "cabeças" de brócolis em cultivo consorciado não diferiram da obtida em monocultura, independentemente da época de transplante da alface.

A produtividade da alface foi influenciada pela época de estabelecimento do consórcio em relação ao transplante de brócolis. Melhores resultados para a alface foram obtidos quando transplantada no mesmo dia que o brócolis (0 DAT), porém os consórcios estabelecidos até 7 DAT do brócolis foram viáveis em relação às suas monoculturas.

O índice de uso eficiência da área foi influenciado pela época de transplante da alface em relação ao transplante do brócolis, reduzindo à medida que se atrasou o transplante da alface.

\section{Literatura Citada}

Barros Júnior, A.P.; Rezende, B.L.A.; Cecílio Filho, A.B.; Pôrto, D.R.Q.; Silva, G.S. da.; Martins, M.

2009 Análise econômica da alface americana em monocultura e consorciada com pepino japonês em ambiente protegido. Bioscience Journal, 25: 82-89.

Bezerra Neto, F.; Andrade, F.V.; Negreiros, M.Z. de.; Santos, J.R.J.J. dos.

2003 Desempenho agroeconômico do consórcio cenoura $\mathrm{x}$ alface lisa em dois sistemas de cultivo em faixa. Horticultura Brasileira, 21 (4): 635-641.

Bezerra Neto, F.; Andrade, F.V.; Santos, J.R.J.J.; Negreiros, M.Z. 2007 Desempenho de sistemas consorciados de cenoura e alface avaliados através de métodos uni e multivariados. Horticultura Brasileira, 25 (4): 514-520.
Caetano, L.C.S.; Ferreira, J.M.; Araújo, M.L. 1999 Produtividade de cenoura e alface em sistema de consorciação. Horticultura Brasileira, 17 (2): 143-146.

Cecílio Filho, A.B.; Costa, C.C.; Rezende, B.L.A.; Leeuwen, R. 2008a Viabilidade produtiva e econômica do consórcio entre chicória e rúcula em função da época de plantio. Horticultura Brasileira, 26 (3): 316-320.

Cecílio Filho, A.B.; May, A.

2002 Produtividade das culturas de alface e rabanete em função da época de estabelecimento do consórcio. Horticultura Brasileira, 20 (3): 501-504.

Cecilio Filho, A.B.; Rezende, B.L.A.; Barbosa, J.C.; Feltrin, A.L.; Silva, G.S.; Grangeiro, R.C.

2008b Interação entre alface e tomateiro consorciados em 
ambiente protegido, em diferentes épocas. Horticultura Brasileira, 26 (2): 158-164.

Fukai, S.; Trenbath, B.R.

1993 Processes determining intercrop productivity and yields of component crops. Field Crops Research, 32: 247-271.

Gliessman, S.R.

2005 Agroecologia: processos ecológicos em agricultura sustentável. $3^{\mathrm{a}}$ ed. Porto Alegre: UFRGS. $639 \mathrm{pp}$.

Grangeiro, L.C.; Bezerra Neto, F.; Negreiros, M.Z.; Cecílio Filho, A.B.; Caldas, A.V.C.; Costa, N.,

2007 Produtividade da cultura da beterraba e rúcula em função da época de plantio em monocultivo e consórcio. Horticultura Brasileira, 25 (4): 577-581.

Kolmans, E.; Vásquez, D.

1999 Manual de agricultura ecológica: una introducción a los principios básicos y su aplicación. Habana, Cuba: Actaf, $150 \mathrm{pp}$.

Midmore, D.J.

1993 Agronomic modification of resource use and intercrop productivity. Field Crops Research, 34: 357-380.

Montezano, E.M.; Peil, R.M.N.

2006 Sistemas de consórcio na produção de hortaliças. Revista Brasileira de Agrociência, 12: 129-132.

Muller, A.M.; Paulus, G.; Barcellos, L.A.R.

2000 Agroecologia aplicada: práticas e métodos para uma agricultura de base ecológica. Porto Alegre: EMATER/RS, $86 \mathrm{p}$.

Oliveira, E.Q.; Souza, R.J.; Cruz, M.C.M.; Marques, V.B.; França, A.C.

2010 Produtividade de alface e rúcula, em sistema consorciado, sob adubação orgânica e mineral. Horticultura Brasileira, 28 (1): 36-40.
Paula, P.D.; Guerra, J.G.M.; Ribeiro, R.L.D.; Cesar, M.N.Z.; Guedes, R.E.; Polidoro, J.C.

2009 Viabilidade agronômica de consórcios entre cebola e alface no sistema orgânico de produção. Horticultura Brasileira, 27: 202-206.

Raij, B.V.; Cantarella, H.; Quaggio, J.A.; Furlani, A.M.C. 1997 Recomendações de adubação e calagem para o Estado de São Paulo, 2.ed. Campinas: Instituto Agronômico \& Fundação IAC, 285 p.

Rezende, B.L.A.; Canato, G.H.D.; Cecílio Filho, A.B.

2005 Influência das épocas de cultivo e do estabelecimento do consórcio na produção de tomate e alface consorciados. Ciências e Agrotecnologia, 29 (1): 77-83.

Rezende, B.L.A.; Canato, G.H.D.; Cecílio Filho, A.B.

2003 Productivity of lettuce and radish cultivations as a function of spacing and of time of establishment of intercropping cultivation. Acta Horticulturae, 607: 97-101.

Rezende, B.L.A.; Cecílio Filho, A.B.; Feltrim, A.L.;

Costa, C.C.; Barbosa, J.C.

2006 Viabilidade da consorciação de pimentão com repolho, rúcula, alface e rabanete. Horticultura Brasileira, 24 (1): 36-41.

Rezende, B.L.A.; Cecílio Filho, A.B.; Pôrto, D.R.Q.; Barros

Júnior, A.P.; Silva, G.S.; Barbosa, J.C.; Feltrim, A.L.

2010 Consórcios de alface crespa e pepino em função da população do pepino e época de cultivo. Interciencia, 35: 374-379.

Sinoquet, H.; Caldwell, R.M.

1995 Estimation of light capture and partitioning in intercropping systems. In: Sinoquet, H.; Cruz, P. (Ed.). Ecophysiology of tropical intercropping. pp. 79-98. 
